\title{
Intramedullary spinal cord tumor presenting as the initial manifestation of metastatic colon cancer: case report and review of the literature
}

\author{
G Grasso $^{*, 1}$, F Meli ${ }^{1}$, R Patti $^{2}$, F Giambartino $^{2}$, AM Florena ${ }^{3}$ and DG Iacopino ${ }^{1}$ \\ ${ }^{1}$ Neurosurgical Clinic, Department of Clinic Neuroscience, University of Palermo, Palermo, Italy; ${ }^{2}$ Department of \\ Anesthesiology, University of Palermo, Palermo, Italy; ${ }^{3}$ Institute of Human Pathology, University of Palermo, \\ Palermo, Italy
}

\begin{abstract}
Study design: Case reports and review of the literature.
Objective: Intramedullary spinal cord metastases (ISCMs) are rare type of central nervous system (CNS) involvement of systemic malignant tumors. Since the advent of new neuroradiological techniques, their detection have become increasingly diagnosed in recent years and, although somewhat controversial, surgical treatment has been considered a valid option.

Setting: Neurosurgical Clinic, Department of Clinic Neuroscience, University of Palermo, Italy.

Method: The authors describe the case of a 61-year-old woman who was admitted presenting with progressive tetraplegia. Investigations revealed an intramedullary spinal cord lesion at the cervical level. Magnetic resonance imaging of the brain did not reveal other CNS metastatic lesions.

Result: Patient underwent surgical treatment. The tumor was resected and the patient's neurologic deficits slowly improved. Histological examination of the lesion showed the typical features of a colon carcinoma metastasis. Patient was referred for proper oncological treatment but, unfortunately, she died of disseminated disease within 2 months.

Conclusion: Although uncommon, spinal cord metastases should be considered in the differential diagnosis of ISCM in order to rationalize the decisional-making process and improve the quality of life for these patients.
\end{abstract}

Spinal Cord (2007) 45, 793-796; doi:10.1038/sj.sc.3102105; published online 17 July 2007

Keywords: adenocarcinoma; intramedullary tumor; metastasis

\section{Introduction}

Intramedullary spinal cord metastases (ISCMs) are rare occurrences representing $8.5 \%$ of central nervous system (CNS) metastases. ${ }^{1}$ They affect $0.1-0.4 \%$ of all cancer patients and comprise $1-3 \%$ of all intramedullary spinal cord neoplasms. ${ }^{2,3}$ Basically, ISCMs arise from primary lung cancer, being the small cell carcinoma the most common neoplasm, with the remainder originating from primary cancers of the breast, kidney, and from melanomas or lymphomas. ${ }^{4}$ To date, colon carcinomarelated metastasis is extremely rare with only few cases reported in the literature. ${ }^{4-12}$

We report on a patient with an intramedullary metastasis as first presentation of a colon carcinoma without intracranial involvement. Total resection of the

*Correspondence: G Grasso, Neurosurgical Clinic, Department of Clinic Neurosciences, University of Palermo, Via del Vespro 129, 90100 Palermo, Italy tumor led the asymptomatic tumor to be diagnosed and brought the patient 2 months of useful life. The clinical features and the role of surgical treatment, along with the review of the literature, are presented.

\section{Case report}

\section{History and examination}

This 61-year-old woman had the insidious onset of numbness of the entire right hemibody below the clavicle and weakness of the upper and lower extremities, without pain or sphincter dysfunction.

Patient underwent magnetic resonance imaging (MRI) of the spine, which showed a solitary 2-cm mass occupying almost the entire spinal cord at C3-C4 level. The lesion appeared slightly hyperintense on $\mathrm{T} 1-$ and T2-weighted images, enhancing heterogeneously with intravenous contrast (Figure 1). At presentation to our 
a

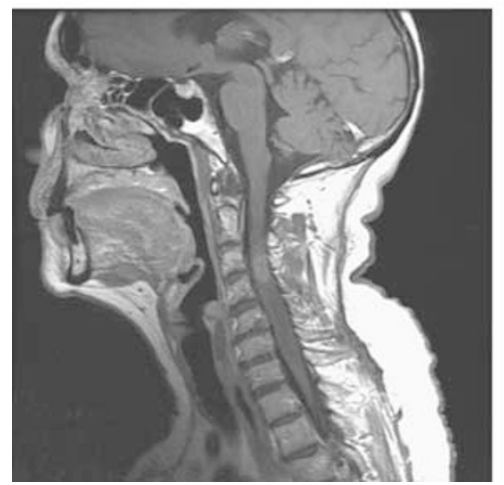

b

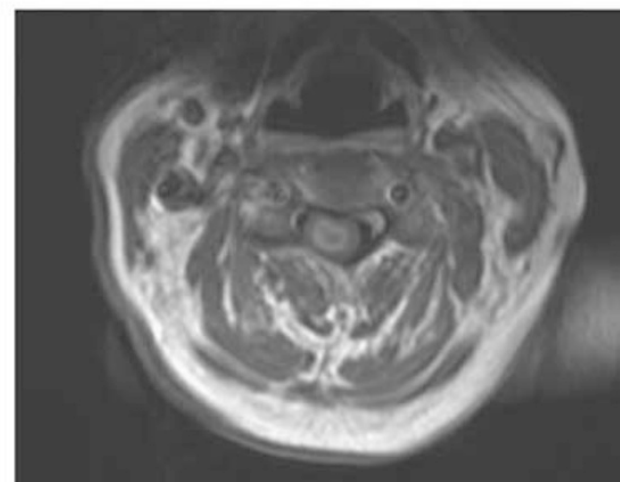

Figure 1 MRI scan of the cervical spinal cord: sagittal (a) and axial (b) gadolinium MRI of the cervical spine showing a solitary mass in the intramedullary cervical spinal cord at C3-C4 level. The lesion showed a heterogeneous enhancement following intravenous administration of gadolinium contrast

Institution, the patient denied pain, fever, weight loss, visual symptoms, or a family history of malignancy.

At neurological examination, she had a spastic bilateral hemiparesis and was diffusely hyper-reflexic, with upgoing toes bilaterally. Sensory examination showed absence of pain and temperature sense below the clavicle, with preserved sense of discriminatory touch. General physical examination was almost negative. Based on the progressive neurological worsening, surgical treatment was performed.

\section{Operation}

Patient underwent C3-C4 laminectomy accomplished via a posterior approach. At operation, the dura appeared to be intact. Once exposed, the spinal cord appeared normal on the surface. After a midline myelotomy was performed, the tumor was discovered. It was red in color with a pseudocapsule distinguishing it from the surrounding spinal cord. The lesion was sharply dissected out and completely removed.

On histological examination, the lesion showed the pathological features of adenocarcinoma metastasis from a colon cancer (Figure 2).

\section{Postoperative course}

The immediate postoperative course was uneventful. The patient progressively showed remarkable neurological recovery and was referred to the oncological department for stadiation of the primary tumor and proper treatment. Unfortunately, she died of disseminated disease within 2 months.

\section{Discussion}

ISCMs are uncommon neoplastic lesions and account for 3-5\% of cases of myelopathy in patients affected by cancer. ${ }^{13,14}$ In the literature, lung cancer, especially small cell carcinoma, accounts for a majority of cases followed by breast cancer, melanoma, lymphoma, and

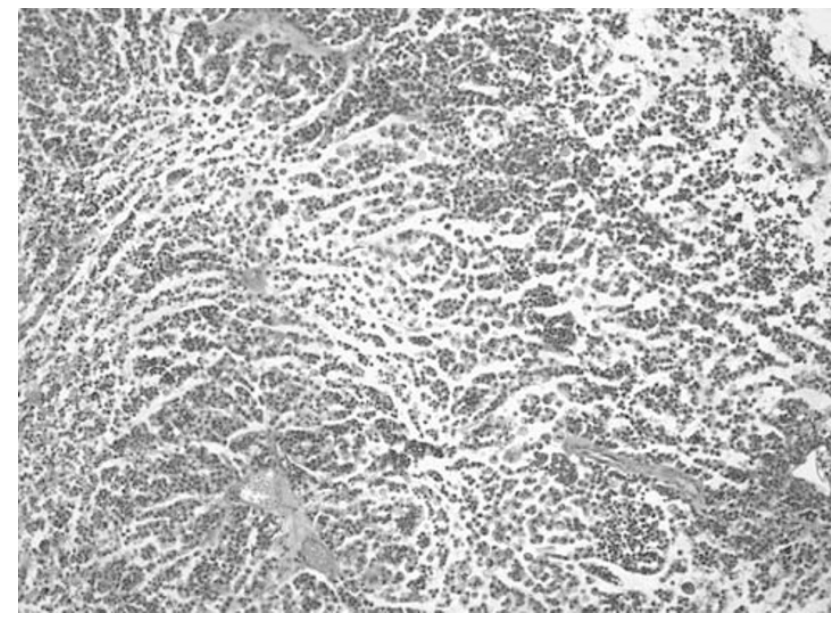

Figure 2 Photomicrograph of the spinal cord lesion showing a colon cancer metastasis $(H \& E$ stain, $\times 20)$

renal cell carcinoma. ${ }^{15,16}$ Colon carcinoma-related metastasis is extremely rare and only few cases have been reported, so far, in the literature. ${ }^{4-12}$ Table 1 summarizes the principal findings of these cases.

Our report describes a unique case in which a patient, without previous history of cancer, presented with a lesion of the cervical tract of the spinal cord proven a metastasis from colon carcinoma. In such a case, the spinal cord lesion was the first clinical evidence of the primary tumor. Although the surgical treatment provided an initial neurological restoration, the patient died of disseminated disease within few weeks. In this regard, it is well known that a majority of patients with ISCM are known to have brain metastases and systemic metastasis at the time of diagnosis. ${ }^{17}$ Furthermore, intramedullary localization is associated with a very short life expectancy with a median survival of 3-4 months from the time of the diagnosis., ${ }^{4,18}$

A controversial issue regarding the natural history of CNS metastases is the discrepancy between spinal cord and brain localization being the latter more frequently 
Table 1 Review of case reports of patients with IMSC colon cancer metastasis

\begin{tabular}{|c|c|c|c|c|}
\hline Author & Level & $\begin{array}{l}\text { Initial } \\
\text { presentation }\end{array}$ & $\begin{array}{l}\text { Other CNS } \\
\text { metastasis }\end{array}$ & Surgery \\
\hline Sansoy $^{9}$ & Thoracic & No & No & No \\
\hline $\begin{array}{l}\text { Silva and } \\
\text { McSwain }^{10}\end{array}$ & Cervical & No & No & Yes \\
\hline Walker $^{11}$ & Lumbar & No & No & No \\
\hline \multirow[t]{2}{*}{ Jellinger $e t a l^{6}$} & $\begin{array}{l}\text { Thoraco- } \\
\text { lumbar }\end{array}$ & No & Yes & No \\
\hline & Cervical & No & Yes & No \\
\hline Foster et $a l^{5}$ & Cervical & No & ND & Yes \\
\hline \multirow[t]{2}{*}{$\begin{array}{l}\text { Schiff and } \\
\text { O'Neill }^{4}\end{array}$} & ND & ND & ND & ND \\
\hline & ND & ND & ND & ND \\
\hline Ogino et $a l^{8}$ & Cervical & No & No & Yes \\
\hline Yano et $a l^{12}$ & Thoracic & No & No & Yes \\
\hline Kaya et $a l^{7}$ & Thoracic & No & Yes & Yes \\
\hline Present case & Cervical & Yes & No & Yes \\
\hline
\end{tabular}

ND, not described

reported. Intramedullary metastasis is rarely the unique site of CNS involvement since brain metastasis may be discovered concurrently or previously in most patients. $^{6,14,19}$ Such a discrepancy can be partially explained by a different mechanism of tumor spreading. Several theories have been postulated, including hematogenous dissemination through either the arterial supply to the spinal cord or retrograde spread from the venous system. ${ }^{6}$ In this regard, it is well known that the brain receives about one-third of the cardiac output through large vessels under high pressure, while the spinal cord receives its arterial supply from small vessels under low pressure. ${ }^{10,13}$ The medullary arteries arise from the aorta at right angles, while the cerebral arteries are almost a direct extension of the aorta, thus favoring embolic seeding. ${ }^{20}$ Metastasis spreading may also occur through direct extension along nerve roots, perineural sheaths and via the CSF pathways. ${ }^{6,21}$ However, hematogenous routes probably account for most ISCM. Finally, the known lower incidence of ISCM can attributed to the fact that the spinal cord is frequently omitted from routine autopsies and patients with widespread metastatic disease who experience neurological dysfunction may be treated without an extensive clinical and neuroradiological evaluation. ${ }^{18}$

Diagnosis of an intramedullary tumor can be difficult even when the primary tumor is known, because clinical findings do not help to distinguish ISCM from other spinal cord lesions. Such an occurrence should be considered when the patient, with a history of malignancy, presents with paresis or sensory impairments. It should be taken into account that a number of noncompressive myelopathies can occur in cancer patients with similar presentations. The differential diagnosis should include radiation myelopathy, paraneoplastic necrotizing myelopathy, and meningeal carcinomatosis. ${ }^{6,22}$ Factors useful in making a diagnosis include pain on presentation, time course, and CSF cytology. Radiation myelopathy and necrotizing myelopathy typically do not present with pain. ${ }^{22}$ The progression of neurological deficits is extremely rapid with ISCM, whereas it is more insidious for these other conditions. CSF findings in ISCM are usually negative or show only an increase in protein and a mild pleocytosis. ${ }^{2,18,22}$ If positive, meningeal involvement may have occurred. Obviously, all of these factors are important but when a spinal lesion is suspected in a patient with a history of malignancy, MRI with gadolinium enhancement should be performed. In our case, although spinal cord MRI was performed at the beginning of the neurological involvement, there was no suspicion of ISCM because it was a solitary lesion and there were no other signs or symptoms of systemic malignancy.

ISCM management after diagnosis remains controversial since the current recommendations are based on anecdotal experiences described in retrospective reports. The standard therapy is radiation treatment, with or without steroids. ${ }^{6,18,23}$ Efficacy of radiation therapy modality has been reported. However, this has been limited to patients in whom a very early diagnosis was made or who had radiosensitive tumors. ${ }^{18,24}$ In these cases, radiotherapy has been demonstrated effective in improving both neurological symptoms and survival. ${ }^{4}$

Modern radiotherapy techniques, such as intensitymodulated radiation therapy, cyberknife, or tomotherapy can hold promise in efficacy, however, so far, no considerable data support their use. It must be noted, however, that only radiosensitive metastases, such as small cell carcinoma, breast cancer, or lymphoma respond to radiation therapy. Studies on the efficacy of chemotherapy are limited but show no effect on survival. ${ }^{25}$

To date, surgery for ISCM should considered in selected ISCM patients, especially those presenting with previously undiagnosed or limited primary tumors, since it may improve the length and quality of survival. ${ }^{26,27} \mathrm{In}$ these cases, radiotherapy and chemotherapy should follow the surgical treatment in order to maximize the treatment result. Several factors are important when considering surgical treatment such as patient's age, physical condition, location, and severity of the primary neoplasm, as well as other metastases, and surgical risks. It should be pointed out that surgical treatment is mainly limited by the fact that these neoplasms often tend to be present after the disease is widespread and life expectancy is short after diagnosis. Therefore, in these cases the optimal management is related to adjuvant chemo- and radiotherapy. Accordingly, surgical treatment should be considered when dealing with a radioresistant single metastasis, in the early stage of the diagnostic process, and in absence of multiple systemic metastases. In these cases, microsurgical removal of ISCM can improve the quality of life and provide a firm diagnosis in cases featuring our report in which the metastatic nature of the spinal cord lesion cannot be suspected. 


\section{Conclusion}

ISCMs are rare but after the advent of MRI they are being encountered with increasing frequency. Colon adenocarcinoma metastases are rarely reported since only few cases are described in the literature.

Early diagnosis and microsurgical resection can result in improvement in neurological deficits and in the quality of life of patients with an ISCM.

\section{References}

1 Lee SS et al. Intramedullary spinal cord metastases: a single-institution experience. J Neurooncol 2007.

2 Costigan DA, Winkelman MD. Intramedullary spinal cord metastasis. A clinicopathological study of 13 cases. J Neurosurg 1985; 62: 227-233.

3 Dunne JW, Harper CG, Pamphlett R. Intramedullary spinal cord metastases: a clinical and pathological study of nine cases. $Q J$ Med 1986; 61: 1003-1020.

4 Schiff D, O’Neill BP. Intramedullary spinal cord metastases: clinical features and treatment outcome. Neurology 1996; 47: 906-912.

5 Foster O, Crockard HA, Powell MP. Syrinx associated with intramedullary metastasis. $J$ Neurol Neurosurg Psychiatry 1987; 50: 1067-1070.

6 Jellinger K, Kothbauer P, Sunder-Plassmann E, Weiss R. Intramedullary spinal cord metastases. J Neurol 1979; 220: 31-41.

7 Kaya RA, Dalkilic T, Ozer F, Aydin Y. Intramedullary spinal cord metastasis: a rare and devastating complication of cancer - two case reports. Neurol Med Chir (Tokyo) 2003; 43: 612-615.

8 Ogino M, Ueda R, Nakatsukasa M, Murase I. Successful removal of solitary intramedullary spinal cord metastasis from colon cancer. Clin Neurol Neurosurg 2002; 104: 152-156.

9 Sansoy OM. Intramedullary spinal cord metastasis from carcinoma of the colon simulating acute ascending myelitis. Mo Med 1955; 52: 864-866.

10 Silva YJ, McSwain B. Intramedullary spinal cord metastasis: the sole clinical manifestation of an adenocarcinoma of the colon. Can J Surg 1967; 10: 341-344.

11 Walker Jr LG. Intramedullary spinal cord metastasis from carcinoma of the colon. Am Surg 1967; 33: 422-424.

12 Yano $\mathrm{S}$ et al. Intramedullary spinal cord metastasis: two case reports and literature review. No Shinkei Geka 2002; 30: 189-196.
13 Edelson RN, Deck MD, Posner JB. Intramedullary spinal cord metastases. Clinical and radiographic findings in nine cases. Neurology 1972; 22: 1222-1231.

14 Hashizume Y, Hirano A. Intramedullary spinal cord metastasis. Pathologic findings in five autopsy cases. Acta Neuropathol (Berl) 1983; 61: 214-218.

15 Fakih M, Schiff D, Erlich R, Logan TF. Intramedullary spinal cord metastasis (ISCM) in renal cell carcinoma: a series of six cases. Ann Oncol 2001; 12: 1173-1177.

16 Mut M, Schiff D, Shaffrey ME. Metastasis to nervous system: spinal epidural and intramedullary metastases. J Neurooncol 2005; 75: 43-56.

17 Connolly Jr ES, Winfree CJ, McCormick PC, Cruz M, Stein BM. Intramedullary spinal cord metastasis: report of three cases and review of the literature. Surg Neurol 1996; 46: 329-337; discussion 37-38.

18 Grem JL, Burgess J, Trump DL. Clinical features and natural history of intramedullary spinal cord metastasis. Cancer 1985; 56: 2305-2314.

19 Murphy KC et al. Intramedullary spinal cord metastases from small cell carcinoma of the lung. J Clin Oncol 1983; 1: 99-106.

20 Tanghetti B, Fumagalli GL, Giunta F, Marini G, Zorzi F. Intramedullary spinal cord metastases. J Neurosurg Sci 1983; 27: 117-124.

21 Mastaglia FL, Kakulas BA. Intramedullary spinal cord metastasis from mammary carcinoma. Paraplegia 1970; 8: 14-18.

22 Winkelman MD, Adelstein DJ, Karlins NL. Intramedullary spinal cord metastasis. Diagnostic and therapeutic considerations. Arch Neurol 1987; 44: 526-531.

23 Tognetti F, Lanzino G, Calbucci F. Metastases of the spinal cord from remote neoplasms. Study of five cases. Surg Neurol 1988; 30: 220-227.

24 Choucair AK. Myelopathies in the cancer patient: incidence, presentation, diagnosis and management. Oncology (Williston Park) 1991; 5: 25-31; discussion 5-7.

25 Holoye $\mathrm{P}$ et al. Spinal cord metastasis in small cell carcinoma of the lung. Int $J$ Radiat Oncol Biol Phys 1984; 10: 349-356.

26 Gasser T, Sandalcioglu IE, El Hamalawi B, van de Nes JA, Stolke D, Wiedemayer H. Surgical treatment of intramedullary spinal cord metastases of systemic cancer: functional outcome and prognosis. J Neurooncol 2005; 73: $163-168$.

27 Gasser TG, Pospiech J, Stolke D, Schwechheimer K. Spinal intramedullary metastases. Report of two cases and review of the literature. Neurosurg Rev 2001; 24: 88-92. 